\title{
DRIVERS' PERCEPTION OF AND RESPONSE TO BRAKE FAILURE
}

\author{
Hamish Jamson* and Paul Smith $\dagger$ \\ *Institute for Transport Studies \\ $\uparrow$ School of Psychology \\ University of Leeds \\ Leeds, U.K. \\ E-mail: hamish@psyc.leeds.ac.uk
}

\begin{abstract}
Summary: The behaviour and emotional state of 48 drivers was investigated during both servo booster and hydraulic circuit brake failures on a proving ground. Results suggested that the most informed and least "stressed" drivers seemed to be the most successful in bringing the test vehicle to a safe stop. The interpretation of these results fed into a study using a driving simulator. Interventions were examined that tested both the "engineering" of the vehicle to a more stringent interpretation of current legislation and driver "information" with a novel visual/auditory warning system. Targeting the vehicle, not the driver, seemed to the best way to manage the rare event of brake failure.
\end{abstract}

\section{INTRODUCTION}

Failures of modern vehicle's braking system are thankfully rare. However, should a driver experience such failure, it is likely to involve either:

- loss of servo assistance ("booster" failure), or

- failure of one of the vehicle's two hydraulic braking systems ("circuit" failure).

In these circumstances, European Directive 71/320/EEC and United Nations ECE Regulation Number 13 state that a vehicle must be able to achieve a deceleration of $2.9 \mathrm{~ms}^{-2}$ with $500 \mathrm{~N}$ of brake pedal effort applied by the driver. But as only $4-5 \%$ of brake activations in normal driving involve deceleration rates higher than this figure (Newcomb, 1981), it might be assumed that the likelihood of an incident requiring rapid deceleration and the simultaneous occurrence of a brake failure is small.

Vehicles are designed such that the vast majority of brake failures are partial, leaving a driver with significant braking still available. However, according to the U.K. Government's Department for Transport (2001), reports have been received that in accidents involving brake failure, drivers have not been achieving even the low levels of deceleration required to avoid an incident. Drivers appear to perceive that they have suffered total brake failure as opposed to the actual partial failure. Drivers may misperceive brake failure due to the change in brake pedal feel and pedal travel associated with booster and circuit failures. A further influence on driver behaviour may be due to a panic or fear reaction. Adrenalin production has the side effect of attenuating perception and control of the environment. Hence, during brake failure, a "panicked" or "stressed" driver may instinctively respond inappropriately. 
This study was undertaken in two parts, conducted both with a real vehicle, a Ford Mondeo, during closed-road tests (MIRA Dunlop and Handling Proving Ground) and in a fixed-base driving simulator (Leeds Driving Simulator).

\section{PROVING GROUND STUDY}

\section{Method}

There were two main experimental factors: brake type and driver information. There were three levels of the within-subjects factor brake type: no failure (brakes functioning normally), circuit failure (half system hydraulic failure) and servo failure (failure of the brake booster). Compared to normally operating brakes, during circuit failure the brake pedal became very spongy and pedal travel increased severely. Only half of the normal deceleration was available. During servo failure, the brake pedal became very stiff, pedal travel decreased dramatically and around ten times the effort was required to achieve the same deceleration as with full boost.

There were also three levels of the between-subjects factor driver information: no information, handbook and brake warning lamp. Drivers in the no information group received no additional information regarding the vehicle's braking system and had to rely on their own knowledge. Twenty-four hours prior to the study, participants in the handbook group read, and were tested on, sections extracted from the owners' handbook on various topics including, most crucially, braking problems whilst driving. By reading the handbook topics, drivers were indirectly informed of the causes and best response to vehicle brake failure. In the brake warning lamp condition, 30s before needing to apply the brakes, the standard dashboard brake failure warning lamp was illuminated. The driver was forced to interpret the meaning of the warning lamp.

Forty-eight drivers took part in the study, with 16 in each of the three driver information groups. Each group was balanced for gender and age.

A traffic light scenario was set-up on the Proving Ground in order to provoke use of the instrumented vehicle's brakes. Drivers were instructed to approach the traffic lights at 40mph via speed limit signs in the vicinity of the event. On most laps of the circuit, the lights remained green but, on occasions, turned red as the vehicle crossed a light beam. The light becoming red was the cue to brake. Drivers had $58 \mathrm{~m}$ in which to bring the vehicle to a safe stop. During the 50minute trial, each participant performed four stops at the traffic lights. The first was a practice stop with brakes fully functional in order for participants to become familiar with the event. The second stop was always with brakes fully operational and was used as each driver's baseline stopping performance. The third and fourth stops were with either servo or circuit brake failure counterbalanced in order across the participants. The test vehicle recorded brake pedal effort $(\mathrm{N})$, brake line pressure (bar), brake pedal travel $(\mathrm{mm})$ and vehicle speed $(\mathrm{m} / \mathrm{s})$ at $200 \mathrm{~Hz}$. Psychophysiological measures of heart rate and electro-dermal activity were recorded with a BioPac MP100.

\section{Results}

ANOVAs were performed with driving speed as the dependent variable at $5 \mathrm{~m}$ intervals; assumptions of ANOVA were not violated. Figure 1 shows the difference in driving speed between the no failure brake type and the servo failure brake type every $5 \mathrm{~m}$ for the three levels of driver information. There was a similar pattern of behaviour with the circuit failure brake 
type. There was no main effect of information at any point during the stop (at the $58 \mathrm{~m}$ stop line: $\left.\mathrm{F}_{(2,24)}=1.34, \mathrm{p}=0.28\right)$.

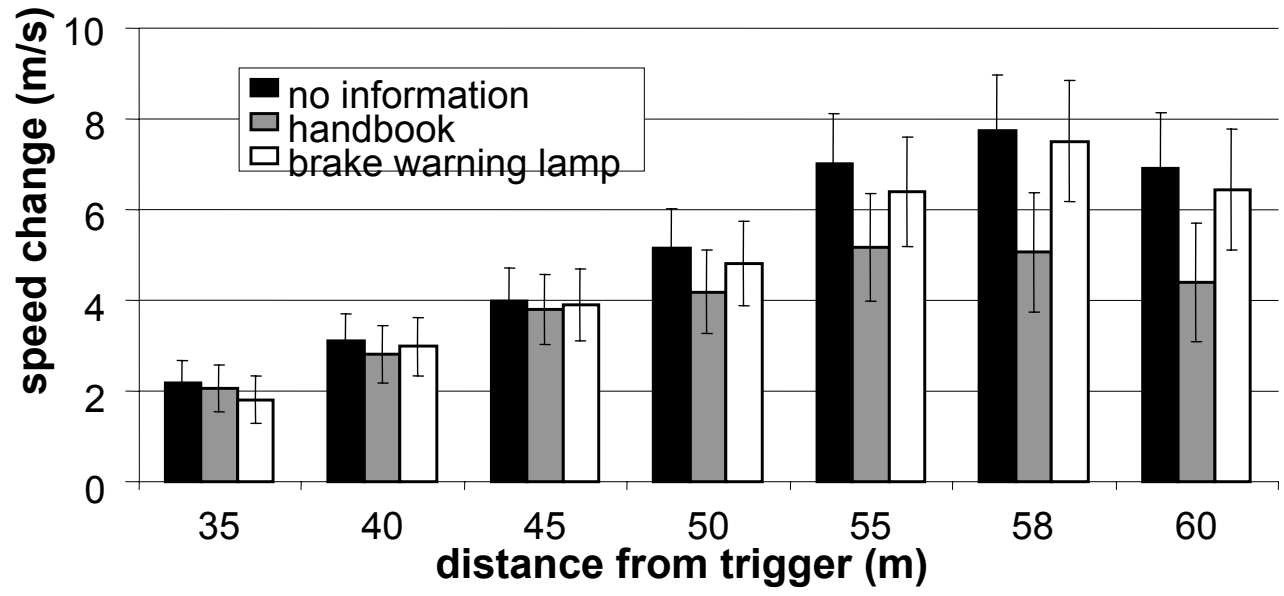

Figure 1. Difference in speed between no failure (baseline) and servo failure by driver information (standard error bars)

Posthoc tests showed that there was no difference between no information and the brake warning lamp in maintaining driver stopping performance close to baseline (no failure) condition (at 58m, Tukey LSD $p=0.90)$. Although not significant, there was a trend that the handbook information was the most effective method of information (at 58m, Tukey LSD p=0.10).

There was a main effect of gender (Figure 2), such that female drivers crossed the stop line at a significantly higher speed than male drivers, compared to their own baseline (no failure) stop $\left(\mathrm{F}_{(2,24)}=4.15, \mathrm{p}=0.045\right)$.

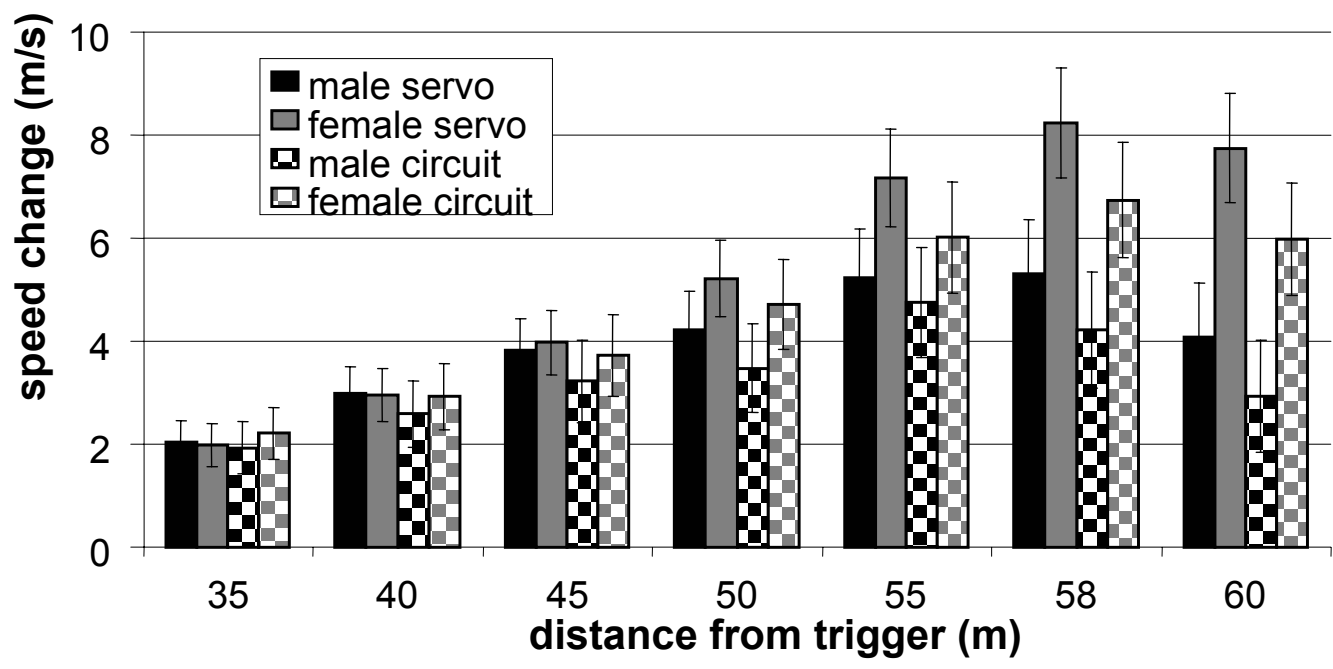

Figure 2. Difference in speed between no failure (baseline) and brake failure by brake type and gender (standard error bars) 
There was no interaction of gender and brake type. However, there was an interaction of gender and information $\left(\mathrm{F}_{(2,24)}=4.32, \mathrm{p}=0.025\right)$, see Table 1 .

Table 1. Interaction of gender and driver information

\begin{tabular}{|c|c|c|c|}
\hline Gender & No information & Handbook & Brake warning lamp \\
\hline Male & $6.92 \mathrm{~m} / \mathrm{s}$ & $4.45 \mathrm{~m} / \mathrm{s}$ & $2.81 \mathrm{~m} / \mathrm{s}$ \\
\hline Female & $6.68 \mathrm{~m} / \mathrm{s}$ & $4.55 \mathrm{~m} / \mathrm{s}$ & $11.24 \mathrm{~m} / \mathrm{s}$ \\
\hline
\end{tabular}

There was a main effect of brake type $\left(\mathrm{F}_{(1,24)}=3.91, \mathrm{p}=0.048\right)$ such that drivers had a significantly higher speed when crossing the stop line with a servo failure than with a circuit failure.

In terms of participants' psychophysiological activity, changes in heart rate (HR) and electrodermal activity (EDA) were analysed. A change was defined as the difference between HR and EDA recorded during the $5 \mathrm{~s}$ epoque prior to the traffic light event and that measured during the 5 s period during the event (and possible failure). There were no significant differences in either HR or EDA based upon driver information, although those participants who had received the handbook tended to demonstrate lower rates of HR change. There was a significant main effect of gender $\left(\mathrm{F}_{(1,47)}=10.25, \mathrm{p}<.005\right)$ in respect of HR change but not for changes in EDA $\left(\mathrm{F}_{(1,47)}\right.$ $=1.41$, NS). Female drivers showed a greater increase in HR change compared to males.

Independent groups t-tests were then conducted to explore the relationship between driving performance (whether or not participants managed to stop successfully at the stop line of the traffic lights) and physiological state; summary data are shown in. Both $\operatorname{HR}\left(\mathrm{t}_{(47)}=3.32, \mathrm{p}=0.031\right)$ and EDA $\left(t_{(47)}=2.59, p=0.042\right)$ were increased in those participants who failed to successfully stop the vehicle at the traffic lights.

Table 2. Participants HR and EDA Change by performance (stop versus non-stop) to the braking events

\begin{tabular}{|c|c|c|c|c|c|}
\hline Condition & Stop successful? & HR Change & SD & EDA Change & SD \\
\hline \hline Servo Failure & Yes & 22.19 & 21.74 & 1.98 & 1.45 \\
\hline & No & 29.61 & 20.73 & 2.32 & 2.34 \\
\hline Circuit Failure & Yes & 15.56 & 16.49 & 2.10 & 1.22 \\
\hline & No & 28.70 & 22.61 & 2.45 & 1.01 \\
\hline
\end{tabular}

Results of the Proving Ground were interpreted that the illumination of the standard dashboard brake-warning lamp during brake failure was ineffective in aiding drivers to stop effectively. However, there was a trend (and a possible significant effect had the sample size been larger) of handbook information. In addition, drivers who had undergone the least increase in HR and EDA during failure were best able to stop successfully. In essence, the best prepared and least "stressed" drivers seemed to be the most successful. The Driving Simulator study attempted to test in more detail a possible method of implementation of these findings. 


\section{DRIVING SIMULATOR STUDY}

\section{Method}

The objectives were:

- To investigate whether engineering the vehicle (modifications to the vehicle's braking system) towards less "stressful” brake failures might improve drivers' stopping performance under brake failure ("engineering" effects).

- To investigate whether a more novel use of handbook and dashboard warning lamps together might "prepare" a driver for brake failure and hence improve stopping performance ("information" effects).

In terms of "engineering" effects, modifications were made to the braking system to account for possible changes in the existing minimum braking requirements of the current legislation. Three various braking/pedal effort deceleration profiles were implemented in the simulator for servo failure. Deceleration profiles $\mathrm{A}$ and $\mathrm{C}$ both adhered to the minimum requirements of Regulation $13\left(2.9 \mathrm{~m} / \mathrm{s}^{2}\right.$ at $500 \mathrm{~N}$ pedal effort). The difference between them was that they had differing braking thresholds (pedal effort at onset of deceleration). Profile B was a more stringent regulation of $3.2 \mathrm{~m} / \mathrm{s}^{2}$ at $400 \mathrm{~N}$ pedal effort with the higher braking threshold.

"Information" to alert drivers of imminent brake failure was presented to drivers by the provision of a dashboard warning lamp and auditory alarm (visual/auditory warning system). The visual/auditory warning was presented in two different scenarios: pre-failure warning and simultaneous failure warning. Pre-warning was given to the driver around 30s before the braking scenario occurred and was intended to simulate situations when, for example, there may be a slow leak of hydraulic fluid from the braking system. Simultaneous warning only occurred as drivers applied the brakes and mimicked situations such as catastrophic seal failure.

The braking event was scripted such that the experience was identical for each driver. Drivers were instructed to follow a platoon of traffic and to maintain approximately $40 \mathrm{mph}$. The lead vehicle, directly in front of the simulator driver, consistently kept a 2 s headway, regardless of the simulator driver's speed. Other simulated vehicles in the platoon maintained the same speed as the lead vehicle. When the braking event was triggered, the platoon and the lead vehicle decelerated sharply at $7.18 \mathrm{~m} / \mathrm{s}^{2}$, giving the driver $58 \mathrm{~m}$ to bring the simulator to a halt in order to avoid a collision. Oncoming vehicles prevented the simulator driver from simply swerving around the platoon to avoid the collision without braking.

\section{Results}

ANOVAs were performed with driving speed as the dependent variable at $5 \mathrm{~m}$ intervals. "Engineering" (deceleration profiles) was a within-subjects factor for half of the 48 drivers; for the other half, "information" (visual/auditory warning system) was also a within-subjects factor. Figure 3 shows the difference in driving speed between the no failure condition and the three servo failure deceleration profiles every $5 \mathrm{~m}$. There was a significant "engineering" effect: posthoc tests showed that when drivers experienced profile $B\left(400 \mathrm{~N}, 3.2 \mathrm{~m} / \mathrm{s}^{2}\right)$, the change in speed from their no failure stop was significantly less than either profile A (Tukey LSD, $\mathrm{p}=0.038$ ) and profile C (Tukey LSD, $\mathrm{p}=0.047$ ). 


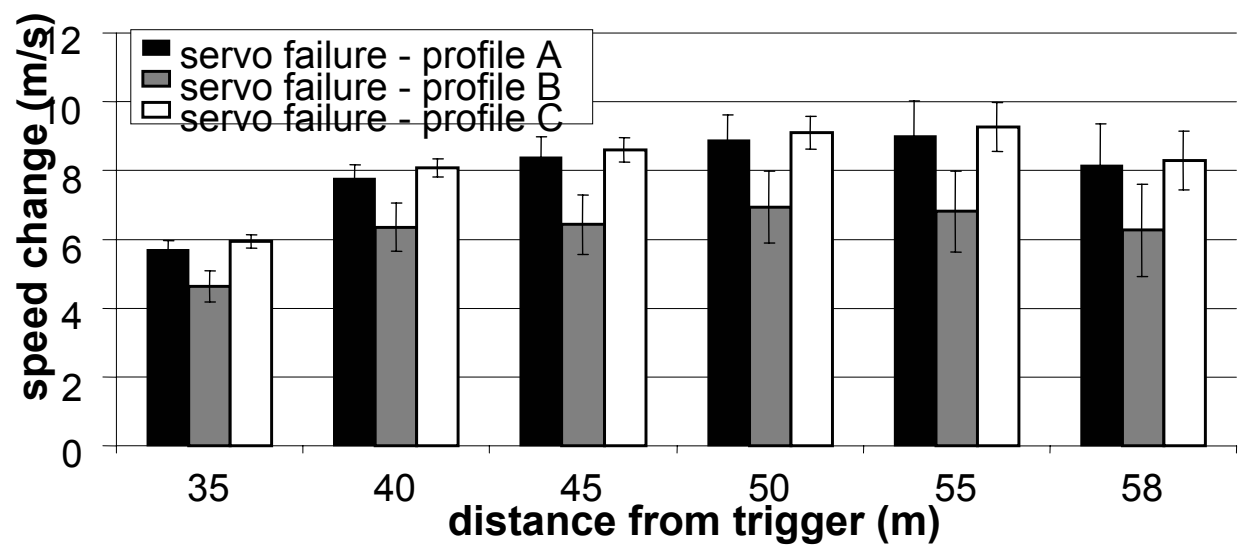

Figure 3. "Engineering" effects: difference in speed between no failure (baseline) and servo failure conditions

Figure 4 shows the "information" effect of the visual/auditory warning system, alerting the driver to impending brake failure. Whilst there was no overall main effect, posthoc tests showed that pre-warning the driver significantly improved stopping performance (Tukey LSD, $\mathrm{p}=0.041$ ). Simultaneous warning tended to improve stopping performance, but the result was not significant (Tukey LSD, $\mathrm{p}=0.18$ ).

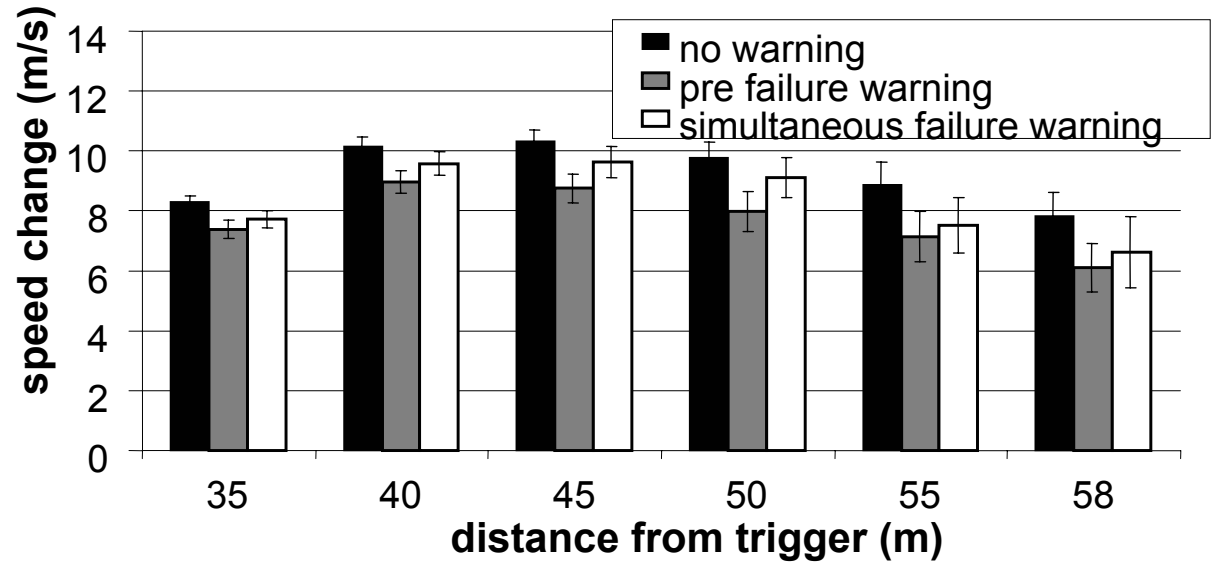

Figure 4. "Information" effects: difference in speed between no failure (baseline) and servo failure warnings

There were no gender differences of either the "engineering" or "information" effects. As in the Proving Ground study, servo failure was more challenging to drivers than circuit failure $\left(\mathrm{F}_{(1,23)}=26.4, \mathrm{p}<0.001\right)$. 
In terms of drivers' psychophysiology, the increase in HR for the servo failure with profile B $\left(400 \mathrm{~N}, 3.2 \mathrm{~m} / \mathrm{s}^{2}\right)$ was found to be significantly less than for the servo A $\left(500 \mathrm{~N}, 2.9 \mathrm{~m} / \mathrm{s}^{2}\right)$ (Tukey LSD, $\mathrm{p}=0.045)$. There was a significant main "information" effect of warning system $\left(\mathrm{F}_{(2,46)}\right.$ $=3.15, p=0.041)$ for HR. HR change was significantly lower for the pre-warning failure compared to the simultaneous and no-warning servo failures (Tukey LSD, $\mathrm{p}<0.05$ ). Measures of EDA did not prove conclusive.

\section{CONCLUSIONS}

In the Proving Ground study, when drivers experienced brake failure there was no proven effect of driver information. The standard dashboard brake warning lamp was ineffective and whilst those drivers who had knowledge of the vehicle handbook tended to brake more efficiently, the effect was not statistically significant. In essence, neither of the "traditional" methods of informing drivers of how best to act in a brake failure situation were totally reliable. Furthermore, elevated levels of arousal were found in those participants who failed to stop at the traffic light, strongly suggesting an association between "stress" and braking performance. Taking these two findings together suggests that targeting the driver in the current fashion may not be the best approach to maximise stopping performance under brake failure. Targeting the vehicle or managing brake failure in order that it becomes less "stressful" might prove to be more effective.

The Driving Simulator study attempted, by "informing" drivers of impending brake failure with a visual/auditory warning system and by "engineering" a potential increase to the deceleration available to drivers during servo brake failure, to evaluate a realisation of the Proving Ground findings. Driver braking performance significantly improved with the introduction of these interventions. In addition, the physiological responses of drivers were lowered during servo failure, reflecting the need for less effort, mental and physical, to slow the vehicle.

Whilst pre-failure warnings significantly improved stopping performance under servo failure, even those warnings received simultaneously with brake application had a positive, but not significant, trend with regard to safety. It should be noted that both pre- and simultaneous failure warnings included an auditory alarm and consequently the physiological reactivity was, to a large extent, determined by this novel stimulus. The increased HR and EDA prior to brake failure and the subsequent reduction in HR and EDA increase during failure reflected an orientating or alerting response produced by the auditory and visual stimuli. In essence, the warning system aroused drivers prior to the impending servo failure and this arousal resulted in improved stopping performance. Furthermore, the reasonably strong gender effects found under servo failure during the Proving Ground study were no longer apparent with the auditory / visual warning.

The realisation of less "stressful" brake failures appeared to improve driver behaviour during brake failure. "Engineering" improved vehicle performance and improved driver "information" through the use of appropriate warning systems might achieve this. Targeting the vehicle and not the driver seems to the best way forward to manage the rare event of brake failure. 


\section{ACKNOWLEDGMENTS}

The authors gratefully acknowledge the U.K. Government's Department for Transport, who funded this study.

\section{REFERENCES}

Department for Transport. (2001). Driver's Perception of the Performance of the Secondary Braking System. PPAD 9/33/73.

Newcomb, T.P. (1981). Driver behaviour during braking. Society of Automotive Engineers.

West Coast International Meeting, Seattle, Washington, August 3-6, 1981. 810832.

[Warrendale, Pa.] 